\title{
Correction to: Quality Improvement and Personalization for Statins: the QUIPS Quality Improvement Randomized Trial of Veterans' Primary Care Statin Use
}

J. B. Sussman, $M D, M S^{1,2,3}$, R. G. Holleman, $M S^{2}$, B. Youles, $M P A^{2}$, and J. C. Lowery, PhD²

'University of Michigan Department of Internal Medicine, Ann Arbor, MI, USA; ${ }^{2}$ VA Center for Clinical Management Research, Ann Arbor, MI, USA;

${ }^{3}$ Institute for Healthcare Policy and Innovation, University of Michigan, Ann Arbor, MI, USA.

$\mathbf{C}$ ORRECTION TO: J GEN INTERN MED

http://doi.org//10.1007/s11606-018-4681-6

Dr. Sussman's name displayed incorrectly in the html of this paper. The correct citation should be Sussman BJ. 